\title{
Are Plant-Based Analogues Replacing Cow's Milk in the American Diet?
}

\author{
Hayden Stewart ${ }^{* \dagger}\left(\mathbb{D}\right.$, Fred Kuchler ${ }^{\dagger}$, Jerry Cessna ${ }^{\dagger}$ and William Hahn ${ }^{\dagger}$ \\ U.S. Department of Agriculture, Economic Research Service, 1400 Independence Ave., SW, Mailstop 1800, Washington, DC, \\ 20250-0002, USA \\ ${ }^{\star}$ Corresponding author. Email: hayden.stewart@usda.gov
}

\begin{abstract}
Retail sales of fluid cow's milk are decreasing while those of plant-based milk analogues are increasing. In this study, we model the relationship between households' purchases of both types of products and perform simulations. Results show that growing consumer demand for plant-based products is causing cow's milk sales to decline somewhat faster than otherwise. However, plant-based products are not a primary driver of sales trends for cow's milk. The decline in cow's milk sales is substantially greater than the rise in sales of plant-based analogues.
\end{abstract}

Keywords: Almond milk; cow's milk; dairy; plant-based analogues; soy milk

JEL Classifications: D12; L15; Q18

\section{Introduction}

Grocery store shelves and refrigerated cases have for many years carried numerous non-dairy products with package labels that include the word "milk," such as almond milk, soy milk, rice milk, oat milk, coconut milk, cashew milk, and pea milk. According to Dairy Management Inc. $(\mathrm{DMI})^{1}$, retail sales of these products reached $8.7 \%$ of the combined milk and non-dairy milk alternative beverage market on a volume (gallons) basis in 2019 (Dairy Management Inc., $2019 \mathrm{~b}$ ). Producers of both cow's milk and plant-based analogues ${ }^{2}$ offer consumers a diverse set of choices. A contributor to Progressive Dairyman, a trade publication serving the U.S. dairy industry, examined his local supermarket's fluid milk case. He found 126 different products including 87 fluid cow's milk products and 39 "milk alternatives" (Covington, 2017).

Are plant-based analogues replacing cow's milk in the American diet? So far, no research speaks directly to whether rising sales of plant-based analogues are reducing sales of cow's milk, although some studies using retail sales data investigate whether the two types of beverages are price complements or substitutes (e.g., Copeland and Dharmasena, 2016; Dharmasena and Capps, 2014). In one study, Dharmasena and Capps (2014) model the demand for soy-based analogues,

\footnotetext{
†The findings and conclusions in this publication are those of the authors and should not be construed to represent any official USDA or U.S. Government determination or policy.

${ }^{1} \mathrm{DMI}$ is the management organization that builds demand for dairy products and is funded by U.S. dairy farmers as well as dairy importers (Dairy Management Inc., 2019a).

${ }^{2}$ There is no universally accepted terminology for describing the group of non-dairy products with package labels that may include the word "milk." The dairy industry objects to "milk" following "almond" or "soy" or the name of any other plant product (see following section of this paper). To remain neutral in this dispute, we follow the lead of the U.S. Food and Drug Administration (FDA), which calls "veggie" burgers a ground beef analogue product (21CFR73.520).
}

( The Author(s) 2020. This is an Open Access article, distributed under the terms of the Creative Commons Attribution licence (http:// creativecommons.org/licenses/by/4.0/), which permits unrestricted re-use, distribution, and reproduction in any medium, provided the original work is properly cited. 


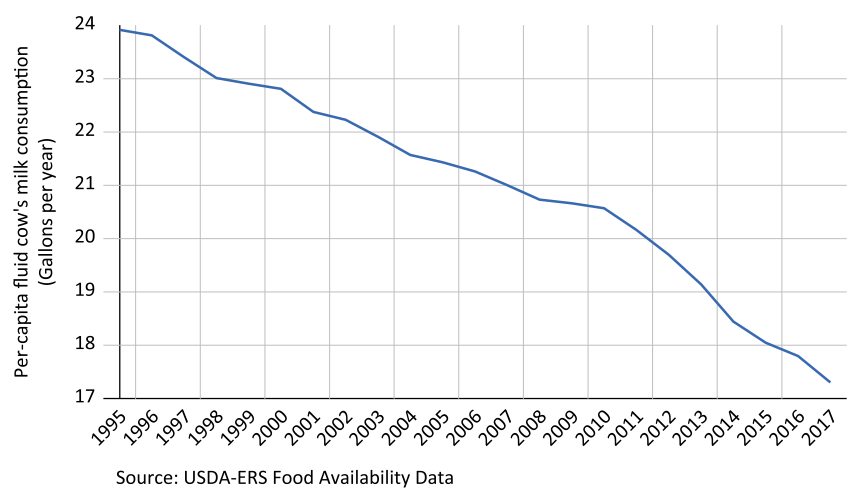

Figure 1. Long-run decline in per-capita fluid cow's milk consumption.

white cow's milk, and flavored cow's milk. Soy-based analogues are found to be a substitute for both types of cow's milk. However, this finding alone does not help to explain observed sales trends. Indeed, it raises additional questions about how cow's milk could have lost market share during a decade in which the product's cost at retail stores decreased (see Section 4).

In this study, using Information Resources, Inc. (IRI) data, we investigate the relationship between American households' purchases of cow's milk and plant-based milk analogues. First, trends in the amounts of each type of product bought by households over the years 2013 to 2017 are examined. Americans' per capita consumption of cow's milk has long been trending downward, but the relatively recent increase in the rate of decline, along with the increase in sales of plant-based products, brings growth rates for the two product categories to the center of policy debates (Figure 1). Here, we seek to quantitatively assess the extent to which growth rates for sales of plant-based milk analogues are related to those for cow's milk.

For our main empirical analysis, we estimate a vector autoregressive (VAR) model and perform simulations. Our simulations draw on the estimated VAR model and quantify how much plantbased milk analogues have been replacing cow's milk. Our simulations also reveal the extent to which current efforts by dairy farmers' agents to press for changes in food labeling regulations might improve cow's milk sales. Dairy industry representatives have been pressing the government to prevent companies from using dairy terms like "milk," "cheese," and "yogurt" on non-dairy products. We do not yet know whether or how policymakers will respond. We also do not know how consumers would react to any changes enacted by policymakers. However, we can consider a range of possibilities based on the historical behavior of Federal regulatory agencies and what the dairy industry and producers of plant-based analogues want. Some actions could have little or no impact. Others would force companies selling plant-based milk analogues to label their products differently and could thereby reduce their product sales.

Our results show that plant-based milk analogues are negatively affecting households' purchases of cow's milk. The rate of replacement may even be about one-to-one in recent years. In other words, every gallon of an analogue purchased by a household may take an equally sized sale away from dairy suppliers. However, the amount of plant-based analogues purchased by households is relatively small compared to cow's milk sales. Thus, the magnitude of the impact on cow's milk sales is also small. Sales of plant-based milk analogues are not a primary driver of sales trends for cow's milk and food labeling policies are unlikely to have a large impact on those trends.

\section{The dairy industry makes its case}

Dairy industry representatives argue that using dairy terms on non-dairy product packaging is deceptive and hurts dairy farmers. The president and CEO of the National Milk Producers 
Federation (NMPF) ${ }^{3,4}$, Jim Mulhern, for one, said it confuses consumers, leading them to assume that the products are nutritionally similar to dairy foods: "We want to end the consumer deception associated with these products" (NMPF, 2017). To stop manufacturers of plant-based analogues from using the word "milk" on product packaging, NMPF and other members of the dairy industry have collectively appealed to all three branches of government including the judiciary, the executive branch, and the U.S. Congress.

Legal challenges to the use of "milk" on plant-based products have thus far failed. In December 2018, the U.S. Court of Appeals for the Ninth Circuit affirmed the district court's order dismissing with prejudice (ending the litigation) a complaint that Blue Diamond Growers mislabeled its products (Painter v. Blue Diamond Growers, Case No. 17-55901). The court concluded that consumers are not deceived by seeing "milk" on almond-based product packages. In 2013, the U.S. District Court, Northern District California similarly dismissed with prejudice a class action suit against several producers of soy-based milk analogues (Ang v. Whitewave Foods Company, Case No. 13-cv-1953).

The dairy industry is also making its case with the U.S. Food and Drug Administration (FDA). ${ }^{5}$ In its appeals to FDA, NMPF has pointed to Federal standards of identity that define milk as "the lacteal secretion, practically free from colostrum, obtained by the complete milking of one or more healthy cows" (21CFR131.110). ${ }^{6}$ In September 2018, FDA published a solicitation in the Federal Register (FR) asking for public comments on the labeling of plant-based products with dairy food names (83 FR 49103). ${ }^{7}$ After reviewing the comments it received, FDA may or may not issue guidance in the future.

Legislation under debate in the U.S. Congress would force FDA to issue guidance prohibiting non-dairy products made from nuts, seeds, plants, and algae from being labeled with dairy terms including milk, yogurt, and cheese. FDA would be required to issue this guidance within 90 days of the effective date of the legislation. The Defending against Imitations and Replacements of Yogurt, Milk, and Cheese to Promote Regular Intake of Dairy Everyday Act (DAIRY PRIDE Act) was reintroduced into the $115^{\text {th }}$ Congress in March 2019. One of the Act's sponsors, Senator Tammy Baldwin (Wisconsin), said, "Mislabeling of plant-based products as "milk" hurts our dairy farmers. That's why I'm reintroducing the DAIRY PRIDE Act to take a stand for Wisconsin farmers and the quality products they make" (Baldwin, 2019).

\section{Trends in milk drinking}

\subsection{Long-run decline in per capita consumption of cow's milk}

Long a dietary staple, Americans' per capita consumption of cow's milk has been decreasing since the 1940s. USDA Economic Research Service's annual Food Availability data ${ }^{8}$ show that, on average, Americans consumed 17.3 gallons of cow's milk per year in 2017 versus 31.3 gallons in 1970 (a nearly 45\% decline) (USDA Economic Research Service, 2019a). Moreover, the rate of decline has recently increased. From 1995 through 2009, per capita consumption fell at an average annual rate of $1.0 \%$. From 2010 to 2017 , the average annual rate of decline was almost $2.5 \%$ (Figure 1$)^{9}$

\footnotetext{
${ }^{3} \mathrm{NMPF}$ describes itself as "the voice of dairy producers on Capitol Hill." It aims to foster an economic and political climate in which dairy producers and the cooperatives they own can thrive and prosper (National Milk Producers Federation, 2019a).

${ }^{4} \mathrm{NMPF}$ has, for example, appealed to the U.S. Food and Drug Administration (FDA). Details of the organization's strategy are available in its "Road Map" Petition to FDA (National Milk Producers Federation, 2019b).

${ }^{5}$ See NMPF's "Road Map" Petition to FDA (National Milk Producers Federation, 2019).

${ }^{6}$ Standards of identity for foods are mandatory, Federally set requirements that determine what a food product must contain in order to be marketed under a certain name in interstate commerce.

${ }^{7}$ The comment period ended on January 28, 2019 (83 FR 58775).

${ }^{8}$ USDA Economic Research Service's Food Availability data are available back to 1909.

${ }^{9}$ Changes in the rate of decrease may substantially alter Americans' future intake of fluid milk. It will take 27.7 years for the level of per capita consumption to fall by half if the annualized rate of decrease remains $2.5 \%$ versus 69.3 years if it were to have remained $1 \%$ per year.
} 
A variety of factors are likely contributing to the persistent decrease in U.S. per capita fluid milk consumption including changes in the nation's demographic composition. For one thing, consumption typically peaks in childhood and drop offs steadily with age (e.g., Moshfegh et al., 2019; Sebastian et al., 2010). Thus, it is important to recognize that younger people account for a shrinking share of the U.S. population. Between 2010 and 2018, the share of the overall U.S. population that is aged less than 10 years decreased from $13.1 \%$ to $12.1 \%$ while that aged 10 through 19 years decreased from $13.8 \%$ to $13.1 \%$ (U.S. Census Bureau, 2019). ${ }^{10}$

Changes in the food environment may be even more important than changes in the nation's demographic composition. A variety of soft drinks, bottled water, and other beverage products have been introduced over the decades and increasingly compete with milk for a share of the consumer's appetite. Fisher et al. (2001), for one, suggest that children's fluid milk consumption may decrease with exposure to competing beverages. Hanson et al. (2005) similarly find that dairy intake is lower among girls in homes where soft drinks are available.

Americans are also consuming more of their meals and snacks at foodservice venues where fluid milk is less commonly consumed. In 2007, spending on food away from home surpassed spending on food at home and, in 2018, expenditures at foodservice outlets reached $54.4 \%$ of total U.S. food spending (USDA Economic Research Service, 2019b). Bowman et al. (2004), among others, suggest that children's fluid milk consumption may decrease with exposure to fast food in particular.

There have also been changes over time in the types of milk that children can receive at school. Beginning with the 2012-2013 school year, USDA has required schools participating in its lunch and breakfast programs to meet stricter nutrition standards. Meals served to children must include a healthier mix of vegetables, more whole grains, and lower-fat milks. Schools cannot offer whole or reduced-fat ( $2 \%$ milkfat) milk. Only low-fat ( $1 \%$ milkfat) or skim milk (less than $0.5 \%$ milkfat) can be served, and, initially, if milk was flavored (e.g., chocolate), only skim milk was allowed. Rules were later changed to allow low-fat flavored milk to be served. Some journalists and policy advocates have argued that these regulations reduce milk drinking by encouraging children to bring bagged lunches from home and increase food waste (e.g., Leach, 2018; Robinson and Mulvany, 2019).

Still other evidence suggests that the downward trend in cow's milk consumption may be difficult to reverse because of generational differences in demand. As successive generations of American children have grown up amid declining rates of fluid milk consumption per person, they may have developed different life-long habits. According to the Dietary Guidelines for Americans, 2010, individuals "who consume milk at an early age are more likely to do so as adults" (p. 38). Using dietary intake surveys collected by USDA between the 1970s and the 2000s, Stewart, Dong, and Carlson $(2012,2013)$ demonstrate that more recent generations consume smaller quantities of fluid milk. Americans born in the 1970s, for example, drank less milk in their teens, twenties, and thirties than did Americans born in the 1960s at the same age points. Those born in the 1980s and 1990s, in turn, appear poised to drink even less milk in their adulthood than those born in the 1970s.

The dairy industry has launched a variety of new products in an effort to build sales. As noted above, supermarkets may now stock over 100 different products in their fluid milk case (Covington, 2017), and still other products are sold in aseptic packaging outside refrigeration. Products are differentiated by fat content, package size, and flavor. There are lactose-free products for those who have trouble digesting lactose as well as acidophilus milk for those whose seek a probiotic drink. Some cow's milk has added DHA Omega-3. Some cow's milk is further labeled USDA Organic and/or non-GMO. Hardwood and Drake (2018) investigate what types of

\footnotetext{
${ }^{10}$ The American Community Survey is an ongoing survey administered by the U.S. Census Bureau that provides data on the social and economic characteristics of the U.S. population. An online search tool is available with which users can obtain annual data.
} 
consumers demand what types of fluid milk in order to help the dairy industry more effectively market these products and grow sales.

\subsection{Competition within the fluid milk case}

Generational change, the relative popularity of eating out versus eating at home, and changes in the nation's demographic composition, such as aging, are gradual processes. They are not likely responsible for abruptly increasing the rate at which per capita fluid milk consumption has been decreasing since 2010 (Figure 1). Something else may be occurring. One possible cause is growing consumer demand for plant-based milk analogues. Dharmasena and Capps (2014) and Copeland and Dharmasena (2016) outline how soy-based products dominated the market for plant-based milk analogues through 2012 after which they were eclipsed by almond-based products. Sales of almond-based products increased throughout the 2010-2019 decade and drove growth in the overall product category. To be sure, supermarkets carry a variety of plant-based milk analogues differentiated by plant type, flavor, and package size just like they carry a variety of cow's milk products (Covington, 2017). USDA Organic and non-GMO options are also available. Arguably, by using the word "milk" on packaging, manufacturers are suggesting to consumers that these products are not merely a beverage. They can be consumed with cereal, added to coffee, or used anywhere else cow's milk is used. According to DMI, plant-based products "... represent a challenge to [cow's] milk as they are retail case neighbors and satisfy similar product needs..." (Dairy Management Inc., 2016).

Given the perception that plant-based milk analogues pose a competitive threat to dairy farmers, researchers have modeled consumer demand for them. As noted above, Dharmasena and Capps (2014) model the demand for soy-based milk analogues, white cow's milk, and flavored cow's milk. Having a higher income and a college education are positively associated with purchasing soy-based products. Moreover, soy-based products and both types of cow's milk are price substitutes. Copeland and Dharmasena (2016) then model the demand for soy-based products, almond-based products, white cow's milk, and lactose-free cow's milk. Almond and soy-based products are found to be price complements as are almond-based products and white cow's milk.

Other studies seek to better understand the psychological factors that drive households to purchase cow's milk and plant-based milk analogues. After conducting an online survey of shoppers who purchase cow's milk, plant-based analogues, or both at least 2 to 3 times per month, McCarthy et al. (2017) conclude that animal welfare and environmental concerns are a primary reason why consumers might purchase a plant-based product over cow's milk. They recommend that the dairy industry emphasizes the nutritional value of cow's milk, educates consumers about misconceptions they might have regarding cow's milk, and develops lactose-free products that are also appealing to consumers in flavor.

\section{Evidence from household-level retail purchase data}

Data from IRI can be used to study households' purchases at retail food stores. IRI household scanner data are derived from the National Consumer Panel (NCP), an operational joint venture owned by IRI and The Nielsen Company (Muth et al., 2016). Participating households keep scanners in their homes. Panelists use these scanners to record their food purchases after each shopping occasion at a retail food store (e.g., supermarket, supercenter, convenience, or warehouse club store). A limitation of the data is that panelists do not record purchases at foodservice outlets, including restaurants and schools. ${ }^{11}$

\footnotetext{
${ }^{11}$ USDA data suggest that about $85 \%$ of all fluid milk is sold in retail outlets, primarily for home consumption (Lin et al., 2016).
} 
Table 1. American households' weekly purchases at retail food stores of fluid cow's milk and plant-based milk analogues

\begin{tabular}{|c|c|c|c|c|c|}
\hline & 2013 & 2014 & 2015 & 2016 & 2017 \\
\hline \multicolumn{6}{|l|}{ Households' weekly average Purchases } \\
\hline Fluid cow's milk & $\begin{array}{c}0.409 \\
\text { Gallons }\end{array}$ & $\begin{array}{c}0.375 \\
\text { Gallons }\end{array}$ & $\begin{array}{c}0.372 \\
\text { Gallons }\end{array}$ & $\begin{array}{c}0.368 \\
\text { Gallons }\end{array}$ & $\begin{array}{c}0.359 \\
\text { Gallons }\end{array}$ \\
\hline Plant-based products & $\begin{array}{c}0.028 \\
\text { Gallons }\end{array}$ & $\begin{array}{c}0.034 \\
\text { Gallons }\end{array}$ & $\begin{array}{c}0.036 \\
\text { Gallons }\end{array}$ & $\begin{array}{c}0.035 \\
\text { Gallons }\end{array}$ & $\begin{array}{c}0.038 \\
\text { Gallons }\end{array}$ \\
\hline \multicolumn{6}{|l|}{ Percentage of households buying } \\
\hline Fluid cow's milk & $93.7 \%$ & $92.6 \%$ & $92.5 \%$ & $92.5 \%$ & $91.9 \%$ \\
\hline - Bought only cow's milk & $71.0 \%$ & $63.6 \%$ & $61.4 \%$ & $61.1 \%$ & $60.5 \%$ \\
\hline - Also bought a plant-based analogue & $29.0 \%$ & $36.4 \%$ & $38.6 \%$ & $38.9 \%$ & $39.5 \%$ \\
\hline Plant-based products & $30.0 \%$ & $37.5 \%$ & $39.6 \%$ & $39.9 \%$ & $40.5 \%$ \\
\hline - Bought only plant-based analogues & $9.2 \%$ & $10.0 \%$ & $9.8 \%$ & $9.7 \%$ & $10.4 \%$ \\
\hline - Also bought cow's milk & $90.8 \%$ & $90.8 \%$ & $90.2 \%$ & $90.3 \%$ & $89.6 \%$ \\
\hline Number of households in data set & 62,492 & 63,637 & 63,610 & 65,193 & 66,093 \\
\hline
\end{tabular}

Notes: Data are weighted using sample weights to obtain nationally representative estimates. Data do not include products consumed in schools, in restaurants, and in other food-away-from-home establishments.

Source: USDA-ERS Analysis of National Consumer Panel data provided by IRI.

Households participating in the NCP may also fail to report some purchases. To maintain data quality, IRI considers households unreliable if they infrequently report making purchases or report an unrealistically low level of food expenditures (Muth et al., 2016). All other households are included in the company's "static panel" (Muth et al., 2016). While members of the static panel may still omit some purchases and make other reporting errors, research suggests that these problems are of the same magnitude as errors in government-collected data sets commonly used to measure earnings and employment status (Einav, Leibtag, and Nevo, 2008). Among other facets of food markets and consumer behavior, NCP data have been previously used to study trends in the relationship between retail and farm-level dairy prices (Hahn et al., 2016) as well as a household's choice among competing food store types with an application to where it buys cow's milk (Dong and Stewart, 2012).

For this study, we pool IRI-provided NCP data from 2013 to 2017. The composition of the NCP static panel changes from year to year. Some households participated for only one or 2 years. Others remained in the panel for all 5 years under study. The average sample size is about 60,000 households per year (Table 1). We use these data to generate an estimate of how much all U.S. households purchased of both cow's milk and plant-based milk analogues during the 5-year time period. Although the composition of the NCP changes from year to year, IRI provides sample weights that can be used to obtain a nationally representative estimate of U.S. population-level demand for both product categories.

We calculated each household's total purchases of cow's milk and plant-based milk analogues at retail food stores including both refrigerated and unrefrigerated products. ${ }^{12}$ All packages sizes are included and normalized to gallons. ${ }^{13}$ Moreover, in order to be consistent with the USDA

\footnotetext{
${ }^{12} \mathrm{We}$ use a broad definition of milk products in this study that includes unrefrigerated beverages not found in a supermarket's fluid milk case, such as ultra-high temperature (UHT) milk and shelf-stable, plant-based analogues.

${ }^{13}$ This includes pints, quarts, half gallons, and gallons, among other package sizes. Cow's milk is most frequently sold in gallon-sized containers, whereas plant-based milk analogues are most frequently sold in half gallon-sized containers.
} 


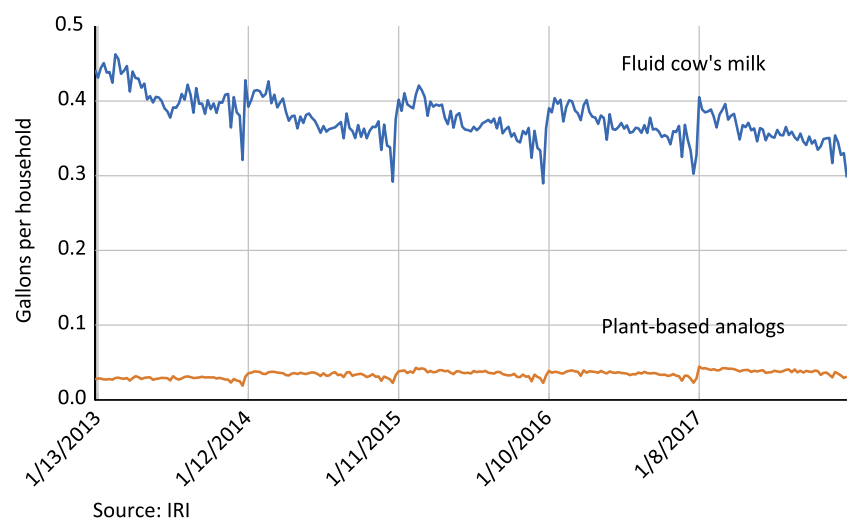

Figure 2. American household's weekly purchases at retail food stores of fluid cow's milk and plant-based analogs.

Economic Research Service's annual Food Availability data for total beverage milk as displayed in Figure 1, we define cow's milk to include skim, low-fat, reduced-fat, and whole milk, as well as flavored cow's milk, acidophilus milk, and buttermilk. In doing so, both organic and conventional products are also included, along with DHA Omega-3 added and non-GMO. Plant-based milk analogues are defined to include beverages manufactured with almonds, soybeans, coconut, rice, flax, oats, and other types of plants as well as products manufactured from two or more types of plant, such as almonds and coconut. ${ }^{14}$ Both organic and conventional products are again included. Excluded from both product categories are nogs, yogurt drinks, smoothies, kefir, horchata, and shakes.

Looking at households' annual purchase patterns in 2017, we find that cow's milk remains a staple food item (Table 1). At some time during the year, 92\% of American households bought cow's milk. And, even among those who bought one or more of the plant-based products considered in this study, $90 \%$ still bought cow's milk.

Weekly data, however, may be better suited to examining consumers' food choices. Research shows that most American households make a weekly, big shopping trip with or without a few small, supplemental trips each week (e.g., Hamrick and McClelland, 2016; Yoo et al., 2006). ${ }^{15}$ We estimated American households' weekly average purchases of cow's milk and plant-based milk analogues. The resulting data set contains 261 weeks of data.

American households bought increasingly less cow's milk and more plant-based milk analogues at retail food stores over the study period. Weekly average purchases of cow's milk declined from about 0.41 gallons per household per week in 2013 to 0.36 gallons per household per week in 2017 (a 12\% decline) (Table 1, Figure 2). By contrast, purchases of almond, soy, and other plantbased milk analogues increased from under 0.03 gallons to over 0.04 gallons per household per week (a 33\% increase). This increase (about 0.01 gallons per week) is roughly one-fifth the size of the decrease in Americans' purchases of cow's milk (about 0.05 gallons per week). Total purchases from the combined cow's milk plus plant-based milk analogues product categories were likewise down between 2013 and 2017.

Our weekly purchase data also show much seasonality. For example, households' reported purchases of both cow's milk and plant-based analogues tend to drop off during the last few

\footnotetext{
${ }^{14}$ Some of these products did not contain the word milk on their packaging; rather some were marketed as a "beverage" or a "drink."

${ }^{15}$ Hamrick and McClelland (2016), for one, examined households' food shopping behavior using the American Time Use Survey. Households participating in USDA's Supplemental Nutrition Assistance Program (SNAP) were estimated to shop for groceries once every 7.2 days. Nonparticipants were estimated to shop once every 6.7 days (p. 15).
} 
months of each year and rebound during the first few months of the next year (Figure 2). ${ }^{16}$ Annual, seasonal, and monthly cycles may exist in the amounts of these products bought by households, in how often households fail to report purchases, or in how often households make mistakes reporting those purchases.

Previous studies found that plant-based milk analogues and cow's milk can be price substitutes (e.g., Dharmasena and Capps, 2014). This could help to explain why cow's milk sales are decreasing at an accelerated rate (Figure 1), but only if prices for plant-based products have been falling relative to those for cow's milk. The Bureau of Labor Statistics (BLS) reports monthly average retail prices for a variety of food products as a part of its effort to estimate inflation rates. These data show that the average retail price of a gallon of whole milk decreased between 2015 through 2018. Moreover, it finished the decade at $\$ 3.19$ in December 2019, about $\$ 0.05$ less than the same product's average retail price in January 2010 (\$3.24) (U.S. Bureau of Labor Statistics, 2020). The IRI-provided NCP data allow us to further examine relative price trends for the two different product categories. Both series fluctuated over time but neither exhibited a clear upward or downward trend. In the first week of January 2013, the average amount paid by NCP households for cow's milk was $\$ 3.60$ per gallon and that for plant-based products was $\$ 6.04$ per gallon. By contrast, in the last week of December 2017, the average amount paid for cow's milk was $\$ 3.34$ per gallon and that for plant-based milk analogues was $\$ 6.12$ per gallon. Given these price movements, it follows that any downward trend in demand for cow's milk brought about by plant-based milk analogues is not explained by the two products' cross-price elasticity of demand.

\section{Co-movements in sales of cow milk and plant-based milk analogues}

\subsection{The model}

The first thought of an economist intent on explaining changing consumption patterns might be to model the probability that a household with certain economic and demographic characteristics purchased a particular type of "milk." This could be done using a discrete choice model. Additional equations could further account for a household's conditional level of purchases using, possibly, a double-hurdle or Heckit framework. However, the present study seeks to explain trends in aggregate sales of cow's milk and plant-based analogues, not household-level behavior. Estimating such a model, if feasible, would also require making many assumptions and model results may be sensitive to those assumptions. For one thing, it would be necessary to allow for temporal linkages. That is, an individual household's milk purchases in 1 week are not likely independent of the same household's purchases in the immediately prior or subsequent week. In order to ascertain whether sales of plant-based analogues are reducing sales of cow's milk, it would also be necessary to interact the conditional amounts of each type of "milk" that a household buys. One approach would be to include the quantity of plant-based analogues purchased among the explanatory variables in the equation that determines conditional purchases of cow's milk and vice versa. However, this approach would require identifying suitable instrumental variables in order to avoid endogeneity bias. Given our data, it is not clear that such instruments exist.

Alternatively, using our household data and IRI-developed sample weights, we can estimate U.S. population-level sales of both cow's milk and plant-based milk analogues. A VAR model can then be employed to model with minimal assumptions whether aggregate sales of plant-based analogues are reducing aggregate sales of cow's milk. A VAR model starts with the possibility that both variables are endogenous and that feedback flows from growth rates for dairy milk to growth rates for plant-based products as well as the reverse. This type of model has been shown

\footnotetext{
${ }^{16}$ Seasonal patterns for household fluid milk purchases shown in Figure 2 differ from seasonal patterns for total fluid milk consumption in the U.S. since the latter includes school milk, which is usually lowest in the summer months when most schools are not in session.
} 
to perform well when used to describe and forecast time series phenomena (e.g., Stock and Watson, 2001).

In this study, we chose to estimate a reduced form VAR model. Formally, this type of model summarizes co-movements among multiple time series variables. Each variable can be written as a function of its own past and the past of all other endogenous variables in the system. Given an (nx1) vector of time series variables, $Y_{t}$, we can write a VAR model with $p$ lags of each endogenous variable (i.e., a $\operatorname{VAR}(p)$ model) as:

$$
Y_{t}=\sum_{i=1}^{p} A_{i} Y_{t-i}+B C_{t}+D X_{t}+\varepsilon_{t}
$$

where $p$ may be determined by the Akaike information criterion (AIC), $C_{t}$ is a matrix of deterministic terms including an intercept and time trend, $X_{t}$ is a matrix of exogenous variables that account for the seasonal movements of the two endogenous variables, and $\epsilon_{t}$ is a vector of unobservable zero-mean white noise processes. $A_{i}, B$, and $D$ are all coefficient matrices. $\operatorname{A~VAR}(p)$ model can be estimated equation-by-equation using OLS. Because the same right-hand-side variables appear in all equation (1), OLS is consistent and as efficient as a seemingly unrelated regression (SUR) model.

In the current study, there are two endogenous variables (i.e., $n=2$ equations). These two variables are American households' weekly average purchases of cow's milk and plant-based milk analogues. Both are expressed in log differences to capture growth rates. In other words, our model is designed to answer the question: To what extent are changes in sales of plant-based milk analogues related to changes in sales of cow's milk and vice versa?

Variables to account for seasonality are also included in the model. While we could have used a set of 52 weekly dummy variables, a more parsimonious approach recognizes that seasonality causes continuous wave-like up and down movements in reported product sales throughout each year. As such, generalized sinusoidal waveforms may better capture the phenomena in question (e.g., Doran and Quilkey, 1972; Kuchler et al., 2018; Van Tassell and Whipple, 1994; Waugh and Miller 1970). ${ }^{17}$ Using the cosine rule for addition/subtraction of angles, the value of each sinusoid during each week of the time series is expressed as a linear combination of a sine function, $\operatorname{Sin}(2 \pi t / L)$, and a cosine function, $\operatorname{Cos}(2 \pi t / L)$, where $L=52 / S$ is the cycle's length in weeks and $t=0,1,2, \ldots, 261$ indicates the week of the time series. For example, if $S=1$, then a full cycle lasts 52 weeks from beginning to end. One full cycle occurs each year. By contrast, if $S=2$, then a full cycle lasts half as long, taking $52 / 2=26$ weeks from beginning to end. There are two of these cycles per year.

Finally, we include an intercept and a linear time trend in each of our model's equations. While our data are at a relatively high frequency (weekly), many of the factors responsible for trends in cow's milk consumption, such as generational change and changes in the nation's demographic composition, are slow and gradual processes taking place over years and even decades. Our intercept and time trend should capture their effects. Specifically, the intercept term should capture exogenous growth or decline in product sales and the time trend allows that exogenous rate of growth to evolve over time. Together, these two deterministic variables describe how sales of cow's milk and plant-based analogues would have changed over the years without interference from each other and seasonality.

\subsection{Model estimation and results}

Using estimates of U.S. population-level growth rates for sales of cow's milk and plant-based milk analogues derived from our IRI-provided NCP data, we estimated the above VAR model with

\footnotetext{
${ }^{17}$ Doran and Quilkey (1972), for one, demonstrate that harmonic analysis is a simple and efficient way to account for the seasonal components of a time series.
} 
Table 2. Vector autoregression estimates (and standard errors)

\begin{tabular}{|c|c|c|c|c|}
\hline & \multicolumn{2}{|c|}{$\begin{array}{l}\text { Change in purchases of } \\
\text { plant-based products }\end{array}$} & \multicolumn{2}{|c|}{$\begin{array}{c}\text { Change in cow's milk } \\
\text { purchases }\end{array}$} \\
\hline Change in log cow's milk purchases $(-1)$ & $-0.5149^{\star \star \star}$ & $(0.1757)$ & $-1.0221^{\star \star \star}$ & $(0.0968)$ \\
\hline Change in log cow's milk purchases $(-2)$ & $-0.6034^{\star \star \star}$ & $(0.2252)$ & $-0.7539^{\star \star \star}$ & $(0.1241)$ \\
\hline Change in log cow's milk purchases $(-3)$ & $-0.5132^{\star \star}$ & $(0.2361)$ & $-0.5913^{\star \star \star}$ & $(0.1301)$ \\
\hline Change in log cow's milk purchases $(-4)$ & $-0.7359^{\star \star \star}$ & $(0.2355)$ & $-0.6339^{\star \star \star}$ & $(0.1298)$ \\
\hline Change in log cow's milk purchases $(-5)$ & $-0.9696^{\star \star \star}$ & $(0.2387)$ & $-0.7447^{\star \star \star}$ & $(0.1315)$ \\
\hline Change in log cow's milk purchases $(-6)$ & $-1.0993^{\star \star \star}$ & $(0.2417)$ & $-0.6977^{\star \star \star}$ & $(0.1332)$ \\
\hline Change in log cow's milk purchases $(-7)$ & $-0.627^{\star \star \star}$ & $(0.2297)$ & $-0.3742^{\star \star \star}$ & $(0.1266)$ \\
\hline Change in log cow's milk purchases $(-8)$ & -0.2494 & $(0.174)$ & -0.115 & $(0.0959)$ \\
\hline Change in log purchases of analogues $(-1)$ & $-0.6829^{\star \star \star}$ & $(0.0923)$ & 0.00105 & $(0.0508)$ \\
\hline Change in log purchases of analogues $(-2)$ & $-0.8163^{\star \star \star}$ & $(0.1082)$ & $-0.1485^{\star \star}$ & $(0.0596)$ \\
\hline Change in log purchases of analogues $(-3)$ & $-1.0071^{\star \star \star}$ & $(0.1202)$ & $-0.2852^{\star \star \star}$ & $(0.0663)$ \\
\hline Change in log purchases of analogues (-4) & $-0.671^{\star \star \star}$ & $(0.1314)$ & $-0.1482^{\star \star}$ & $(0.0724)$ \\
\hline Change in log purchases of analogues $(-5)$ & $-0.4855^{\star \star \star}$ & $(0.1292)$ & -0.0701 & $(0.0712)$ \\
\hline Change in log purchases of analogues $(-6)$ & $-0.283^{\star \star}$ & $(0.118)$ & -0.0523 & $(0.065)$ \\
\hline Change in log purchases of analogues $(-7)$ & $-0.2498^{\star \star}$ & $(0.1066)$ & -0.0497 & $(0.0588)$ \\
\hline Change in log purchases of analogues $(-8)$ & $-0.1527^{\star}$ & $(0.0918)$ & -0.054 & $(0.0506)$ \\
\hline \multicolumn{5}{|l|}{ Seasonality variables } \\
\hline $\operatorname{Cos}(2 \pi t /(52 / 1))$ & $0.0486^{\star \star \star}$ & $(0.0074)$ & $0.0272^{\star \star \star}$ & $(0.0041)$ \\
\hline $\operatorname{Cos}(2 \pi t /(52 / 2))$ & $-0.0125^{\star}$ & $(0.0071)$ & -0.00514 & $(0.0039)$ \\
\hline $\operatorname{Cos}(2 \pi t /(52 / 3))$ & $-0.0304^{\star \star \star}$ & $(0.0079)$ & $-0.018^{\star \star \star}$ & $(0.0044)$ \\
\hline $\operatorname{Cos}(2 \pi t /(52 / 4))$ & $-0.0498^{\star \star \star}$ & $(0.008)$ & $-0.0296^{\star \star \star}$ & $(0.0044)$ \\
\hline $\operatorname{Cos}(2 \pi t /(52 / 5))$ & $-0.0381^{\star \star \star}$ & $(0.0072)$ & $-0.0214^{\star \star \star}$ & $(0.004)$ \\
\hline $\operatorname{Sin}(2 \pi t /(52 / 1))$ & $0.0615^{\star \star \star}$ & $(0.0082)$ & $0.0185^{\star \star \star}$ & $(0.0045)$ \\
\hline $\operatorname{Sin}(2 \pi t /(52 / 2))$ & $0.1143^{\star \star \star}$ & $(0.0106)$ & $0.0518^{\star \star \star}$ & $(0.0058)$ \\
\hline $\operatorname{Sin}(2 \pi t /(52 / 3))$ & $0.0648^{\star \star \star}$ & $(0.0077)$ & $0.0226^{\star \star \star}$ & $(0.0042)$ \\
\hline $\operatorname{Sin}(2 \pi t /(52 / 4))$ & $0.0129^{\star}$ & $(0.0071)$ & 0.00307 & $(0.0039)$ \\
\hline $\operatorname{Sin}(2 \pi t /(52 / 5))$ & 0.001581 & $(0.0071)$ & 0.00384 & $(0.0039)$ \\
\hline \multicolumn{5}{|l|}{ Deterministic variables } \\
\hline Intercept & 0.0112 & $(0.0096)$ & -0.00485 & $(0.0053)$ \\
\hline Trend $(t=1,2,3, \ldots, 252)$ & -0.000041 & $(0.00006)$ & 0.000016 & $(0.00003)$ \\
\hline \multicolumn{5}{|l|}{ Model Fit Statistics } \\
\hline$R^{2}$ & 0.569 & & 0.574 & \\
\hline Akaike Information Criterion & -2.454 & & -3.646 & \\
\hline
\end{tabular}

${ }^{\star, \star \star, \star \star \star}=$ statistically significant at the $10 \%, 5 \%$, and $1 \%$ levels. 
8 lags of each endogenous variable ${ }^{18}$ and 5 seasonal cycles ${ }^{19}$ in each equation. Below, we discuss model diagnostics and estimation results. All results are shown in Table 2.

Diagnostics pointed to the model satisfying standard statistical requirements. Consistency of the VAR parameters, for one, requires that the residuals are not serially correlated. Residual serial correlation was examined with the autocorrelation Lagrange multiplier (LM) test, which reports the multivariate LM test statistics for residual serial correlation up to a specified order. Tests were conducted up to order 9. There was no evidence of serial correlation.

Given that our model's dependent variables are expressed in log differences, we expect both of them to be stationary. Augmented Dickey-Fuller (ADF) and the Kwiatowski-Philips-SchmidtShin (KPSS) tests confirmed that expectation ${ }^{20}$ and further diagnostics confirmed that the system satisfies dynamic stability conditions. ${ }^{21}$

Finally, estimation results show that most right-hand-side variables are statistically significant at conventional levels (Table 2). ${ }^{22}$ But viewing parameter estimates and their individual statistical significance alone is not sufficient for the two endogenous variables. We therefore performed Granger causality tests. That is, if one endogenous variable Granger causes another, then its lags are jointly significant on the right side of the other variable's equation. Results confirmed that weekly purchases of plant-based milk analogues Granger cause weekly purchases of cow's milk $(P$ value $=0.0007)$ and vice versa $(P$ value $=0.0011) .^{23}$

\section{Robustness tests}

Many factors besides sales growth for plant-based milk analogues could conceivably affect retail sales of cow's milk. Some possible causes are gradual processes and should be captured by our model's time trends, such as demographic and generational change. Others could be considered missing variables. These include changes in households' disposable income and changes in sales of other beverage products outside the dairy case.

To examine the importance of disposable income in influencing cow's milk sales, we followed Gicheva, Hastings, and Villas-Boas (2010) recommendation to treat gasoline prices as a proxy for disposable income in food demand. ${ }^{24}$ That is, we added weekly growth in retail gasoline prices as a third variable in the model, leaving lag length unchanged and maintaining the same set of deterministic and exogenous variables in the model. Like growth rates for sales of cow's milk and plantbased analogues, ADF and KPSS tests confirmed that the all grades gasoline weekly price series growth rate does not contain a unit root. The estimated VAR also continued to satisfy tests for dynamic stability and LM tests continued to show no evidence of serial correlation in residuals. However, there was no evidence that gasoline prices affected the estimated VAR. Granger

\footnotetext{
${ }^{18}$ The AIC was minimized with eight lags of each endogenous variable.

${ }^{19}$ We allow for cycles with length $52 / 1,52 / 2,52 / 3,52 / 4$, and 52/5.

${ }^{20}$ Researchers commonly perform both the ADF and the KPSS tests. The two tests are complementary. Non-stationarity is the null hypothesis in the ADF test, whereas stationarity is the null hypothesis in the KPSS test. First, applying an ADF test in the most general form with a constant and a linear trend, we rejected the null hypothesis that each series contains a unit root (both $P$ values $<0.0001$ ). Second, we applied the KPSS test and failed to reject the null hypothesis that each series is stationary.

${ }^{21}$ Inverse roots of AR characteristic polynomial were all within the unit circle.

${ }^{22}$ Results for our intercept and time trend are an exception. Although these two variables were found to be statistically insignificant, we continue to include them in our model. According to Rob J. Hyndman's blog post, "Statistical tests for variable selection," researchers should not focus on statistical significance when deciding which variables to include and drop from a model. "Tests on coefficients are answering a different question from whether the variable is useful in forecasting. It is possible to have an insignificant coefficient associated with a variable that is useful for forecasting (Hyndman, 2019)."

${ }^{23}$ We do not rely on Granger causality tests to show a causal relationship between growth rates for the two product categories. We perform this test for the sole purpose of checking whether each variable is a statistically significant predictor of the other before proceeding with our simulation discussed below (i.e., the lags of one variable improve the 1-step ahead forecast of the other variable). We draw no other conclusions based on it.

${ }^{24}$ Data are available from the U.S. Energy Information Administration (U.S. Energy Information Administration, 2019).
} 
causality tests showed the gasoline price growth rate did not affect and was not affected by the variables in our model. In sum, adding gasoline price growth rates to account for shocks to disposable income did not significantly affect our VAR results so there is no reason to suspect that this variable would qualitatively affect simulation results (discussed below).

We also re-estimated our model including weekly sales growth rates for carbonated beverages (also derived from our IRI-provided NCP data). Granger causality tests showed that growth in carbonated beverage sales affected and were affected by sales growth for both types of milk. However, when we re-ran our simulations, we found that the relationship between cow's milk and plant-based analogues was not substantially affected. The relationship under study is largely independent of carbonated beverage sales and excluding this variable from our model does not bias results of that relationship.

Results for both alternative specifications of the model are available upon request.

\section{What effect might FDA guidance have?}

NMPF and some members of the U.S. Congress want FDA to issue guidance that would prohibit dairy terms from being used for non-dairy products. It is unclear how FDA will respond.

While we cannot predict policymakers' future courses of action or how consumers might respond to any change in product labels, we can consider a range of possibilities and use our VAR model to conduct corresponding counterfactual simulations. Specifically, we can design these simulations to ask how much greater cow's milk sales could have been in 2017 if sales of plant-based milk analogues had grown more slowly between 2013 and 2017. Our baseline simulation assumes that producers of plant-based milk analogues were allowed to use dairy terms on product packaging as they historically did between 2013 and 2017. We then compare Americans' demand for cow's milk in 2017 as predicted by our model for this baseline versus three shock scenarios in which the demand for plant-based analogues grew more slowly over the 5-year time period due to FDA having already limited the use of dairy terms outside of dairy products at the beginning of 2013 .

Our simulation is a two-step process designed to capture both sales growth rates and sales levels. First, because our model's dependent variables were expressed in log differences, we can use our estimated VAR model to predict weekly growth rates for both product categories. For the baseline scenario, this is done by setting the error term in both equations equal to zero for all time periods. In other words, we assume there were no shocks to the system. ${ }^{25}$ Growth rates for both products are predicted by our model's 16 autoregressive terms ${ }^{26}$ two deterministic terms, and five seasonal cycles only. Second, we can then use the estimated growth rates from the first step with the amount of cow's milk households bought at an initial time period (week 1) to predict the value of Americans' purchases of cow's milk in levels in all weeks. For example, the predicted level of purchases in week 2 is the level of purchases in week one multiplied by one plus the estimated weekly rate of growth from week 1 to week 2 . The predicted level of purchases in week 3 is likewise the predicted value in week two times one plus the estimated rate of growth from week 2 to week 3 , and so on.

The same two-step process described above can be adapted for each of our three shock scenarios. Compared with the baseline, we include a weekly shock in our model's error terms. This shock effectively lowers the value of the intercept term in our equation for the rate of growth in sales of plant-based analogues. For our illustration, we consider shocks that would have effectively reduced this sales growth rate over 2013 to 2017 to about two-thirds of the baseline (weekly shock

\footnotetext{
${ }^{25}$ Our simulation sample includes 252 weeks of data. We have 260 observations on our dependent variables after taking differences. We are then missing data on the value of the autoregressive terms on the right-hand side of our model for the first 8 weeks. The 10 week in 2013 is treated as week 1 . The 11 week in 2013 is treated as week 2, and so on.

${ }^{26}$ There are eight autoregressive variables for each of the two endogenous variables in each equation.
} 
$=-0.002$ ), one-third of the baseline (weekly shock $=-0.004$ ), and allowed for zero growth in plant-based analogue sales over the 5-year period (weekly shock $=-0.006$ ).

Finally, we focus on what our simulation predicts the difference would have been in both the growth rate and in the level of weekly average cow's milk purchases in 2017 between our baseline and each of the 3 shock scenarios. To obtain standard errors for the estimated differences, we used a bootstrap procedure..$^{27}$ Our results are shown in Table 3.

Simulation results reveal that plant-based analogues are reducing demand for cow's milk. Slowing the rate at which sales of plant-based analogues are growing would lead to positive changes in the weekly growth rate for cow's milk (last set of columns of Table 3). In other words, sales of cow's milk would have decreased at a slower rate between 2013 and 2017, if Americans had not increased their purchases of plant-based analogues as quickly as they did.

Differences are also found in the level of cow's milk bought by American households between our baseline and shock scenarios. Indeed, under the assumptions behind our simulation, if sales of plant-based analogues had been held between zero and two-thirds of the baseline, Americans purchases of cow's milk might have been about 0.01 gallons per week greater in 2017 (last 2 rows of second column in Table 3 ), ${ }^{28}$ roughly equal to the amount that sales of plant-based analogues grew in both our simulation and in the real world over the time period (Table 1). ${ }^{29}$ This suggests that the displacement ratio may be nearly one-to-one. ${ }^{30}$ However, it should also be remembered that the increase in plant-based analogue sales between 2013 and 2017 was only about one-fifth the size of the decrease in of cow's milk sales (Table 1), confirming that other factors are largely responsible for declining rates of fluid milk consumption.

\section{Discussion}

Per capita cow's milk consumption has been decreasing for about 80 years, and USDA Economic Research Service Food Availability data show that the rate of decrease has accelerated in recent years. U.S. dairy farmers and their representatives further believe that plant-based milk analogues are contributing to this increase in the rate of decrease. They have taken their case to the courts, FDA, and the U.S. Congress, charging producers of plant-based products with using deceptive labeling practices. Changes in food labeling policies may or may not be needed to clear up consumer confusion about differences between the two types of products. However, our results show that such polices are unlikely to alter the fact that Americans have been decreasing their per capita consumption of cow's milk at an accelerated rate in recent years. While plant-based milk analogues are causing cow's milk consumption to decline at a faster rate than otherwise, they account for a relatively small share of overall trends.

Previous research has found that plant-based products and cow's milk can be price substitutes (e.g., Dharmasena and Capps, 2014). However, because relative prices have not changed much,

\footnotetext{
${ }^{27} \mathrm{~A}$ model-based resampling procedure was used. We first fit the model. In order to preserve the dependency between our two error terms, we then extracted pairs of residuals. Totally, 10,000 pseudo data sets were next created. For each time period in each pseudo data set, we selected a pair of residuals at random to serve as the innovations. We then built up our pseudo data sets based on the assigned innovations and our estimated model parameters. Our VAR(8) model was subsequently re-estimated using each pseudo data set. Diagnostics confirmed that residual covariance matrices derived from our model's bootstrap procedure and analytical errors were similar in size and tests of significance based on them reached the same conclusions. Finally, we compared predictions for our baseline and shock scenarios for each of 10,000 pseudo data sets.

${ }^{28}$ Differences between our baseline and both scenarios are statistically significant as shown by the $95 \%$ bootstrap confidence intervals reported in Table 3. These confidence intervals also contain 0.01 .

${ }^{29}$ In both our raw data and in our simulated baseline scenario, Americans increased their purchases of plant-based analogues by about 0.01 gallons per household per week between 2013 and 2017, even though we set all error terms equal to zero for this part of our simulation as discussed above.

${ }^{30}$ This only applies to the time period under study. Vegans and other individuals who cannot consume animal products may have been among the early adopters of plant-based analogues, and switching analogues for cow's milk could be only a recent phenomenon.
} 
Table 3. Sales of cow's milk would have been greater in 2017 if sales of plant-based analogues had been growing at a slower rate since 2013 , simulation results

\begin{tabular}{|c|c|c|c|c|c|c|c|}
\hline \multirow{3}{*}{$\begin{array}{l}\text { Assumed growth rate for sales of } \\
\text { plant-based milk analogues }\end{array}$} & \multirow{3}{*}{$\begin{array}{l}\begin{array}{l}\text { Households' weekly average } \\
\text { purchases of cow's milk }\end{array} \\
\text { Gallo }\end{array}$} & \multirow[t]{3}{*}{$\begin{array}{l}\text { Difference in level of } \\
\text { purchases from baseline }\end{array}$} & \multirow{2}{*}{\multicolumn{2}{|c|}{$\begin{array}{c}95 \% \text { confidence } \\
\text { interval }\end{array}$}} & \multirow{3}{*}{$\begin{array}{c}\text { Difference in weekly growth } \\
\text { rate from baseline }\end{array}$} & \multirow{2}{*}{\multicolumn{2}{|c|}{$\begin{array}{c}\begin{array}{c}95 \% \text { confidence } \\
\text { interval }\end{array} \\
\% \text { points per week }\end{array}$}} \\
\hline & & & & & & & \\
\hline & & & $\begin{array}{l}\text { Lower } \\
\text { bound }\end{array}$ & $\begin{array}{l}\text { Upper } \\
\text { bound }\end{array}$ & & $\begin{array}{l}\text { Lower } \\
\text { bound }\end{array}$ & $\begin{array}{l}\text { Upper } \\
\text { bound }\end{array}$ \\
\hline Baseline-simulated historical growth & 0.332 & & & & & & \\
\hline One-third lower & 0.337 & +0.00449 & 0.0000764 & 0.0086056 & +0.000059 & 0.0000009 & 0.0001107 \\
\hline Two-thirds lower & 0.341 & +0.00903 & 0.0001527 & 0.017312 & +0.000118 & 0.0000018 & 0.000215 \\
\hline No growth & 0.346 & +0.01364 & 0.0002289 & 0.0264776 & +0.000176 & 0.0000027 & 0.0003322 \\
\hline
\end{tabular}

Notes: To gauge cow's milk demand in our baseline, we allowed the values of both dependent variables to be predicted by our model's 16 autoregressive terms, 2 deterministic terms, and 5 seasonal cycles. Both error terms were equal to zero for all time periods. We then used the estimated growth rates to predict the value of Americans' purchases of cow's milk in levels in all weeks. For example, the predicted level of purchases in week 2 is the level of purchases in week one multiplied by one plus the estimated weekly rate of growth from week 1 to week 2 . The predicted level of purchases in week 3 is the predicted value in week 2 times one plus the estimated rate of growth from week 2 to week 3 , and so on. The same process was then adapted for each of our three shock scenarios. Compared with the baseline, we adjusted the value of our model's error terms to include a weekly shock. For our illustration, we consider shocks that would have effectively reduced the sales growth rate for plant-based analogues over 2013 to 2017 to two-thirds of the baseline (shock $=-0.002$ ), one-third of the baseline (shock $=-0.004)$, and allowed for zero growth in plant-based analogue sales over the 5 -year period (shock $=-0.006$ ). Finally, a bootstrap procedure was then used to test the statistical difference between our baseline and shock scenarios. After fitting the model, we extracted pairs of residuals and created 10,000 pseudo data sets. For each time period in each of these pseudo data set, we selected a pair of residuals at random to serve as the innovations. We then built up our pseudo data sets based on the assigned innovations and our estimated model parameters. Finally, we estimated our VAR(8) model using each pseudo data set. 
this does not help to explain why some consumers are substituting plant-based products for cow's milk; rather, it must be that consumers increasingly treat the two types of products as substitutable, fulfilling similar needs and wants. Moreover, for some consumers, plant-based products must offer a more desirable bundle of attributes for at least some consumption purposes. One possibility is that preferences are changing over time. McCarthy et al. (2017), for example, find that animal welfare and environmental concerns are a primary reason why consumers might buy a plant-based product over cow's milk. If Americans are becoming more concerned with animal welfare and the environment, this could raise demand for plant-based products. Alternatively, manufacturers of these products may have done research to identify the attributes consumers want and are figuring out how to incorporate their findings into products. "[T]hese companies are investing hundreds of millions of dollars and are getting really good at taste, are phenomenal at marketing and great at innovation," said DMI's CEO Tom Gallagher at a February 2019 DMI board meeting (Bunting, 2019). "We have to be honest with ourselves, there will be plant-based beverages out there, and people will buy them, and they will gain share ... it's because the food and beverage companies are doing a great job at what they do."

Additional research into why some consumers are substituting plant-based products for cow's milk might benefit from the use of discrete choice models that can identify which types of consumers are substituting which types of plant-based analogues for which types of cow's milk. While the present study uses a very broad definition of milk and market-level data, it is likely that certain types of consumers are more inclined to substitute a plant-based analogue for cow's milk than others. Rates of substitution may also vary widely between, for example, organic and conventional products or refrigerated and shelf-stable products.

Additional research is also needed to understand whether consumer confusion is or is not contributing to growing demand for plant-based milk analogues. There are at two possible ways that current labeling practices could confuse consumers: (1) the perception that the products contain dairy ingredients in cases where they do not and (2) the perception that the products are nutritionally similar to cow's milk. In a survey of 1,000 adults by the International Food Information Council Foundation (2018), a majority of people surveyed had a correct understanding of which products labeled as "milk" contain cow's milk. However, in a 2018 Consumer Reports survey of 1,003 adults, only $26 \%$ of consumers correctly responded that plant-based milk analogues have less of some key nutrients than cow's milk (protein, calcium, vitamin A, and potassium) (Consumer Reports, 2019). Although the surveys by the International Food Information Council Foundation and Consumer Reports did indicate confusion by at least some people concerning the content and nutritional value of plant-based milk analogues, additional research is needed to ascertain how consumers would respond to any particular changes in food labeling policy and whether removing the word "milk" from the labels of these products would eliminate or reduce the confusion.

Finally, additional research is also needed to explain why cow's milk demand is declining at an accelerated rate, since plant-based milk analogues explain little of that acceleration. However, it should also be noted that Americans' overall dairy foods consumption is stable. USDA Economic Research Service Food Availability data show that increases in demand for other products, such as cheese and butter, are making up for decreases in milk drinking. Progressive Dairyman calls Americans' growing appetite for these other dairy foods "good news" while acknowledging that the slide in fluid consumption remains a "concern" (Natzke, 2017).

Questions about FDA's enforcement of standards of identify are also not unique to cow's milk. The National Cattlemen's Beef Association, for one, has voiced concern over meat analogues and the State of Arkansas has taken steps to limit use of the word "rice" on analogue products (Judkis, 2019). In this environment, economic researchers should expect more questions about how sales of analogue products affect consumer demand for traditional commodities. 
Financial support. This research was supported by the U.S. Department of Agriculture, Economic Research Service.

\section{References}

Baldwin, T. "U.S. Senators Tammy Baldwin and Jim Risch Stand Up for America's Dairy Farmers." Tammy Baldwin United States Senator for Wisconsin, March 14, 2019. Internet site: https://www.baldwin.senate.gov/press-releases/dairy-pride2019

Bowman, S., S. Gortmaker, C. Ebbeling, M. Pereira, and D. Ludwig. "Effects of Fast-Food Consumption on Energy Intake and Diet Quality Among Children in a National Household Survey." Pediatrics 113,1(2004):112-18.

Bunting, S. “DMI CEO on Fluid Milk.” Ag Moos “Growing the Land,” April, 12, 2019. Internet site: https://agmoos.com/2019/ 04/02/dmi-ceo-on-fluid-milk/

Consumer Reports. "Comments of Consumer Reports to the Food and Drug Administration on the Notice and Request for Comments on 'Use of the Names of Dairy Foods in the Labeling of Plant-Based Products' Docket No. FDA-2018-N-3522." Consumer Reports, January 31, 2019. Internet site: https://advocacy.consumerreports.org/wp-content/uploads/2019/02/ CR-FDA-Plant-based-milk-cmmts.pdf

Copeland, A., and S. Dharmasena. "Impact of Increasing Demand for Dairy Alternative Beverages on Dairy Farmer Welfare in the United States." Selected paper presented at the annual meeting of the Southern Agricultural Economics Association, San Antonio, Texas, February 6-9, 2016.

Covington, C. “Are More Products in the Fluid Milk Case a Good or Bad Thing?” Progressive Dairyman, December 12, 2017. Internet site: https://www.progressivedairy.com/topics/management/are-more-products-in-the-fluid-milk-case-a-goodor-bad-thing

Dairy Management Inc. "DMI and the Dairy Checkoff," 2019a. Internet site: https://www.dairy.org/about-dmi (Accessed June 18, 2019).

Dairy Management Inc. "Fluid Milk Retail Report," 2019b. YTD data through May 19, 2019.

Dairy Management Inc. "Retail Monthly Milk Snapshot," 2016. YTD data through December 25, 2016.

Dharmasena, S., and O. Capps. "Unraveling Demand for Dairy-Alternative Beverages in the United States: The Case of Soymilk." Agricultural and Resource Economics Review 43,1(2014):140-57.

Dong, D., and H. Stewart. "Modeling a Household's Choice Among Food Store Types." American Journal of Agricultural Economics 94,3(2012):702-17.

Doran, H. E., and J. J. Quilkey. "Harmonic Analysis of Seasonal Data: Some Important Properties." American Journal of Agricultural Economics 54,4(1972):646-51

Einav, L., E. Leibtag, and A. Nevo. On the Accuracy of Nielsen Homescan Data. Washington, DC: U.S. Department of Agriculture, Economic Research Service, Economic Research Report No. 69, 2008. Internet site: https://www.ers.usda. gov/publications/pub-details/?pubid=46114

Fisher J., D. Mitchell, H. Smiciklas-Wright, and L. Birch. "Maternal Milk Consumption Predicts the Tradeoff Between Milk and Soft Drinks in Young Girls' Diets." Journal of Nutrition 131,2(2001):246-50.

Gicheva, D., J. Hastings, and S. Villas-Boas. "Investigating Income Effects in Scanner Data: Do Gasoline Prices Affect Purchases?” American Economic Review 100,(May 2010):480-84.

Hahn, W., H. Stewart, D. Blayney, and C. Davis. "Modeling Price Transmission Between Farm and Retail Prices: A Soft Switches Approach.” Agricultural Economics 47,2(2016):193-203.

Hamrick, K., and K. McClelland. Americans' Eating Patterns and Time Spent on Food: The 2014 Eating \& Health Module Data. Washington, DC: U.S. Department of Agriculture, Economic Research Service, Economic Information Bulletin No. 158, 2016. Internet site: https://www.ers.usda.gov/publications/pub-details/?pubid=80503

Hanson, N., D. Neumark-Sztainer, M. Eisenberg, M. Story, and M. Wall. "Associations Between Parental Report of the Home Food Environment and Adolescent Intakes of Fruits, Vegetables and Dairy Foods.” Public Health Nutrition 8,1(2005):77-85.

Hardwood, W., and M. Drake. "Identification and Characterization of Fluid Milk Consumer Groups." Journal of Dairy Science 101,10(2018):8860-74.

Hyndman, R. "Statistical Tests for Variable Selection," 2019. Internet site: https://robjhyndman.com/hyndsight/tests2/ (Accessed June 18, 2019).

International Food Information Council Foundation. "What's in a Name? Survey Explores Consumers' Comprehension of Milk and Non-Dairy Alternatives," October 11, 2018. Internet site: https://foodinsight.org/whats-in-a-name-surveyexplores-consumers-comprehension-of-milk-and-non-dairy-alternatives/

Judkis, M. "What's in a Name? The Battle Over Alternative Meat, Milk and Rice Labeling Rages On." The Washington Post, April 11, 2019. Internet site: https:/www.washingtonpost.com/news/voraciously/wp/2019/04/11/whats-in-a-name-thebattle-over-alternative-meat-milk-and-rice-labeling-rages-on/?utm_term=.22af91c0d742 
Kuchler, F., M. Bowman, M. Sweitzer, and C. Greene. "Evidence from Retail Food Markets That Consumers are Confused by Natural and Organic Food Labels." Journal of Consumer Policy, 2018. https://doi.org/10.1007/s10603-0189396-X

Leach, T.. "New USDA Rule Allows Flavored Milk to be Served to 30 Million Children." Dairy Herd, December 7, 2018. Internet site: https://www.dairyherd.com/article/new-usda-rule-allows-flavored-milk-be-served-30-million-children

Lin, B-H., T. Anekwe, J. Buzby, and J. Bentley. U.S. Food Commodity Availability by Food Source, 1994-2008. Washington, DC: U.S. Department of Agriculture, Economic Research Service, Economic Research Report No. 221, 2016. Internet site: https://www.ers.usda.gov/webdocs/publications/81818/err-221.pdf?v=0

McCarthy, K., M. Parker, A. Ameerally, S. Drake, and M. Drake. "Drivers of Choice for Fluid Milk versus Plant-Based Alternatives: What are Consumer Perceptions of Fluid Milk?” Journal of Dairy Science 100,8(2017):6125-38.

Moshfegh, A., A. Garceau, E. Parker, and J. Clemens. Beverage Choices Among Children: What We Eat in America, NHANES 2015-2016. Washington, DC: U.S. Department of Agriculture, Agricultural Research Service, Food Surveys Research Group, Dietary Data Brief No. 22, 2019. Internet site: https:/www.ars.usda.gov/ARSUserFiles/80400530/pdf/DBrief/ 22_Beverage_choices_children_1516.pdf

Muth, M., M. Sweitzer, D. Brown, K. Capogrossi, S. Karns, D. Levin, A. Okrent, P. Siegel, and C. Zhen. Understanding IRI Household-Based and Store-Based Scanner Data. Washington, DC: U.S. Department of Agriculture, Economic Research Service, Technical Bulletin No. 1942, 2016. Internet site: https://www.ers.usda.gov/webdocs/publications/47633/57105_tb1942.pdf? $v=0$

National Milk Producers Federation. “About Us,” 2019a. Internet site: https://www.nmpf.org/about/about-nmpf/about-us/ (Accessed June 18, 2019).

National Milk Producers Federation. "NMPF 'Road Map' Petition to FDA Outlines Next Steps in Dairy-Labeling Rules." News and Resources. February 21, 2019b. Internet site: https://www.nmpf.org/nmpf-road-map-petition-to-fda-outlinesnext-steps-in-dairy-labeling-rules/

National Milk Producers Federation. "NMPF Urges FDA: Enforce U.S. Standards for Dairy Food Labeling." News and Resources. July 25, 2017. Internet site: https://www.nmpf.org/july-25-nmpf-urges-fda-enforce-u-s-standards-for-dairyfood-labeling/

Natzke, D. "Fluid Slide Continues, But There's Some Good News Regarding Dairy Consumption.” Progressive Dairyman. October 31, 2017. Internet site: https://www.progressivedairy.com/news/industry-news/fluid-slide-continues-but-theres-some-good-news-regarding-dairy-consumption

Robinson, P., and L. Mulvany. "Big Dairy is About to Flood America’s School Lunches with Milk.” Bloomberg Businessweek. January 9, 2019. Internet site: https://www.bloomberg.com/news/features/2019-01-09/big-dairy-is-about-to-floodamerica-s-school-lunches-with-milk

Sebastian, R., J. Goldman, C. Wilkinson Enns, and R. LaComb. Fluid Milk Consumption in the United States: What We Eat In America, NHANES 2005-2006. Washington, DC: U.S. Department of Agriculture, Agricultural Research Service, Food Surveys Research Group, Dietary Data Brief No. 3, 2010. Internet site: https:/www.ars.usda.gov/ARSUserFiles/80400530/ pdf/DBrief/3_milk_consumption_0506.pdf

Stewart, H., D. Dong, and A. Carlson. Why Are Americans Consuming Less Fluid Milk? A Look at Generational Differences in Intake Frequency. Washington, DC: U.S. Department of Agriculture, Economic Research Service, Economic Research Report No. 149, 2013. Internet site: https://www.ers.usda.gov/publications/pub-details/?pubid=45075

Stewart, H., D. Dong, and A. Carlson. "Is Generational Change Contributing to the Decline in Fluid Milk Consumption?" Journal of Agricultural and Resource Economics 37,3(2012):435-54.

Stock, J., and M. Watson. "Vector Autoregressions" Journal of Economic Perspectives 15,4(2001):100-15.

U.S. Bureau of Labor Statistics. "Databases, Tables \& Calculators by Subject,” 2020. Internet site: https://www.bls.gov/data/ (Accessed March 30, 2020).

U.S. Census Bureau. “American Community Survey," 2019. Internet site: https://www.census.gov/programs-surveys/acs/ (Accessed December 15, 2019).

U.S. Department of Agriculture and U.S. Department of Health and Human Services. "Dietary Guidelines for Americans, 2010." 2010. Internet site: http://www.cnpp.usda.gov/dietaryguidelines.htm

U.S. Department of Agriculture, Agricultural Marketing Service. Packaged Fluid Milk Sales in Federal Milk Order Markets: By Size and Type of Container, Category, and Distribution Method During November 2015. Washington, DC: U.S. Department of Agriculture, Agricultural Marketing Service, Report No. PFMSR-1115, April 2019. Internet site: https:// www.fmmacentral.com/PDFdata/Container\%20Survey\%202015.pdf

U.S. Department of Agriculture, Economic Research Service. “Food Availability (Per Capita) Data System,” 2019a. Internet site: https://www.ers.usda.gov/data-products/food-availability-per-capita-data-system/ (Accessed June 18, 2019).

U.S. Department of Agriculture, Economic Research Service. "Food Expenditure Series," 2019b. Internet site: https://www. ers.usda.gov/data-products/food-expenditure-series/ (Accessed December 23, 2019). 
U.S. Energy Information Administration. "Petroleum \& Other Liquids," 2019. Internet site: https://www.eia.gov/dnav/pet/ pet_pri_gnd_dcus_nus_w.htm (Accessed December 22, 2019).

Van Tassell, L., and G. Whipple. "The Cyclical Nature of the U.S. Sheep Industry." Journal of Agricultural and Resource Economics 19,2(1994):267-79.

Waugh, F., and M. Miller. "Fish Cycles: A Harmonic Analysis." American Journal of Agricultural Economics 52,3(1970): 422-30.

Yoo, S., T. Baranowski, M. Missaghian, J. Baranowski, K. Cullen, J. Fisher, K. Watson, I. Zakeri, and T. Nicklas.

"Food-Purchasing Patterns for Home: A Grocery Store-Intercept Survey." Public Health Nutrition 9,3(2006):384-93.

Cite this article: Stewart H, Kuchler F, Cessna J, and Hahn W (2020). Are Plant-Based Analogues Replacing Cow's Milk in the American Diet? Journal of Agricultural and Applied Economics 52, 562-579. https://doi.org/10.1017/aae.2020.16 